\title{
Round 3: Regarding Objectivity and Causality - A Rejoinder to Fishman and Miller
}

\author{
BARBARA S. HELD ${ }^{\mathrm{a}, \mathrm{b}}$ \\ ${ }^{\text {a }}$ Department of Psychology, Bowdoin College, Brunswick, ME \\ ${ }^{\mathrm{b}}$ Correspondence concerning this article should be addressed to Barbara S. Held, Department of Psychology, \\ Bowdoin College, 6900 College Station, Brunswick, ME 04011. \\ Email: bheld@bowdoin.edu
}

\begin{abstract}
In this rejoinder I respond separately to Daniel Fishman's and Ronald B. Miller's respective arguments regarding my views about objectivity and causality, owing to the fact that Fishman finds a place for "objectivity" and "causality" within his theoretical model whereas Miller does not. First, I question the basis for Fishman's conclusion that coherence and pragmatic models are objectivist according to my definition of an objectivist epistemology. I also challenge his claim to have included "causal mechanisms" in his pragmatic system of therapy, since he gives them no ontological status other than that of "conceptual tools." Second, I challenge Miller's claim that clinical knowledge cannot be objective knowledge because it is moral knowledge in which what one observes is allegedly determined by one's moral perspective. I also question his insistence that causal explanation in the physical world so departs from causal explanation in the human world that the word "cause" cannot be used in the latter without causing confusion. But if that is so, then the moral accountability and repair that Miller seeks in clinical practice may be hard to obtain.
\end{abstract}

Key words: objectivist epistemology; objectivist ontology; causality; perspectivism; relativism; moral philosophy

That Daniel Fishman and Ronald Miller invited me to comment upon their philosophies of psychotherapy and psychology knowing that I am not like-minded philosophically indicates their uncommon intellectual virtue. Although in some ways I indeed disagree with each of them, as they each do with me, I nonetheless have great respect for their intellectual work: by challenging my arguments, they have helped me to deepen my thinking about these intricate philosophical matters, and for that I am grateful as well.

Since Fishman and Miller respond directly to my comments about objectivity and causality, I have structured this rejoinder along those same lines. But because their views about objectivity and causality are somewhat dissimilar not only from mine but from each other's, in what follows I respond to each of them in separate sections. 
Round 3: Regarding Objectivity and Causality - A Rejoinder to Fishman and Miller

B.S. Held

Pragmatic Case Studies in Psychotherapy, http://pcsp.libraries.rutgers.edu

Volume 2, Module 4, Article 5, pp. 1-11, 10-16-06 [copyright by author]

\section{DANIEL FISHMAN ON OBJECTIVITY AND CAUSALITY}

\section{Objectivity}

As Fishman (2006) rightly states, “'Objectivity’ is such a loaded word and it has such a variety of meanings in the history of philosophy" (p. 5). That is why I was careful to give a definition of it. In his abstract Fishman says that pragmatic psychology has the "capacity, in certain important contexts, to generate statements that are 'objectively true' in Held's definition of this term" (p. 1, abstract). Later he states, "Held's definition of objective knowledge [is] knowledge that is true independent of a particular community of knowers" (p. 5). And he adds,

Pragmatic psychology embraces both coherence and pragmatic truth. It rejects attempts at correspondence (ontological) truth, since as a social constructionist epistemology pragmatic psychology rejects the ability to view the world independent of a particular perspective [italics added]. Since statements that are true within both the coherence and pragmatic theories of truth are true independent of any particular community of knowers, by Held's standard I find statements that are "true" within both the coherence and pragmatic models are objective statements. (p. 6)

I am not sure how Fishman arrived at his conclusion that true statements within coherence and pragmatic models are objective according to my definition of an objectivist epistemology, since their "truth" is indeed relative to or dependent upon (the perspective of) some particular community of knowers. I therefore hope that in his response to this rejoinder he will elaborate his reasoning, as the philosophical waters are deep, and many doctrinal species coexist within them. Let me begin by saying that "my" definition of an objectivist epistemology is one that I have indeed adopted, but it is not one that I constructed. Many contemporary philosophers have put forth some version of it, and in addition to the definition I gave - that "the truth of (or warrant for) a claim does not depend on (or is not relative to) anyone's beliefs about the truth of (or warrant for) a claim" (Held, 2006, p. 17) - they include the notion that objective knowledge does not depend on any particular perspective, paradigm, conceptual scheme, culture, language, theory, discursive community, and so forth (see Erwin, 1997, 1999; Haack, 2002, 2003; Rescher, 1997; Siegel, 2004; Smith, 2004; Thomasson, 2003). For example, according to Erwin (1999),

An "objectivist epistemology" is one which holds that propositions are generally true or false independently of any particular paradigm, or school of thought, or language, or indeed of what any human believes; and furthermore, that they can often be warranted independently of what anyone believes. (p. 353)

Thomasson (2003) said that according to a traditional realist (or objectivist) epistemology, reference to entities in the world "proceeds via a causal relation to an ostended sample, so that the extension of the term is determined by the real nature of the kind rather than by our associated beliefs and concepts" (p. 580). And Haack (2002) stated that realist (or objective) 
Round 3: Regarding Objectivity and Causality - A Rejoinder to Fishman and Miller

B.S. Held

Pragmatic Case Studies in Psychotherapy, http://pcsp.libraries.rutgers.edu

Volume 2, Module 4, Article 5, pp. 1-11, 10-16-06 [copyright by author]

truth "is independent of human beings and their beliefs, concepts, cultures, theories, or whatever" (p. 67).

I used the word "beliefs" in my definition of an objectivist epistemology_Erwin, Thomasson, and Haack each use some version of that word-because beliefs are typically contained within, or even constitute, particular perspectives, paradigms, conceptual schemes, discursive communities, theories, and so forth. And so an objectivist epistemology requires that claims not be made true (or warranted) in virtue of the beliefs that help define the knower's perspective, paradigm, conceptual scheme, discursive community, theory, etc. In all fairness to Fishman, I gave only a bare-bones definition of an objectivist epistemology in my target article; this may have been insufficient.

Still, in his response Fishman does not mention that just prior to my definition of an objectivist epistemology, I gave this definition of an objectivist ontology: "there is a way the world is, which way does not depend on anyone's beliefs about how the world is" (p. 17). I did this because the two go together: if there is not a way that the world is, independent of beliefs about its nature, then how can there be knowledge of the world that is independent of beliefs about the nature of the world? And so one's ontological position has logical implications for one's epistemology, and vice versa.

Fishman seemingly makes knowledge dependent on the knower's perspective (what he calls "pespectivism"), which is consistent with the social constructionist epistemology he adopts. I stated in my target article (p. 16), and elaborate extensively elsewhere (Held, 2007), that one does not need a so-called "view from nowhere" for objective knowledge to obtain; but that is not the same as saying that knowledge can depend on the knower's perspective and still be objective. By my definition it cannot, because inherent in the constructionist's and pragmatist's perspectivism is that warranted claims (i.e., knowledge) depend upon the knower's perspective. But if the knower's perspective (e.g., discursive community, conceptual scheme, or paradigm) contains, or is constituted by, beliefs about how the world is, and knowledge depends on those particular beliefs, then such knowledge is not objective knowledge by my definition.

Fishman makes both the "coherence-based truth" and "pragmatism-based truth" of Statements S1 and S2, respectively, dependent on Knowledge System $\mathrm{K}^{1}$ and $\mathrm{K}^{2}$, respectively (p. 9). Whether this dependence precludes objective knowledge depends on what he means by a "knowledge system." If a knowledge system contains or consists in beliefs about the world, then statements about the world that are judged true according to coherence-based and pragmatismbased theories of truth must depend upon the relevant beliefs of those who operate epistemically within particular knowledge systems (which Fishman, 2006, p. 5, might be willing to call "language communities"). In that case, Statements S1, S2, and all others are not objective by my definition. 
Round 3: Regarding Objectivity and Causality - A Rejoinder to Fishman and Miller

B.S. Held

Pragmatic Case Studies in Psychotherapy, http://pcsp.libraries.rutgers.edu

Volume 2, Module 4, Article 5, pp. 1-11, 10-16-06 [copyright by author]

According to Fishman,

Any perspective can be considered a "knowledge system." ... [W]ithin any perspectival system, it is possible to set forth those conceptual and value assumptions, substantive facts, logic, and other ways of reasoning that are accepted, and those that are not accepted, within the system. (p. 7)

Are beliefs about the world contained within knowledge systems? "Conceptual assumptions" and "substantive facts" might qualify as such beliefs; however, Fishman makes the link between knowledge systems and beliefs (about the world) even more explicit when he appeals to the "linguistic preconditions of knowledge" within the perspectivism he supports: for example, "for Kuhn, the principles are scientific paradigms; for Quine and Feyerband, they are webs of belief; and for Wittgenstein, they are [the structures and rules of] language games" (Fishman, 1999, pp. 87-88, as cited in Fishman, 2006, p. 7).

To sum up, if claims about the world are judged true only relative to (or to be judged true must depend upon) beliefs about the world that are held by those who operate within particular discursive communities (by way of particular paradigms, webs of belief, language games - that is, knowledge systems), then they are not judged true objectively by my definition. "We can never step out of these preconditions and see the world objectively [in the ontological sense]; for our ability to 'see' is dependent upon these preconditions being in place" (Fishman, 1999, pp. 87-88, as cited in Fishman, 2006, p. 7). This is in fact the perspectivism that characterizes the anti-objectivist or relativist epistemology that I and others (who, like me, do not think that objective knowledge requires a view from nowhere) criticize (see Held, 2002, 2007).

\section{Causality}

Causality is of course an ontological matter, and Fishman (2006) denies the possibility of "ontologically objective, scientific knowledge" (p. 7): "Within the context of philosophical pragmatism, the only characteristic that such principles [i.e., "guiding conceptions"] lack is ontological objectivity" (p. 11). Since my definition of epistemological objectivity goes hand in hand with (i.e., depends upon) ontological objectivity, that is another reason why Fishman's epistemology is not objectivist in my sense. What can it mean to say that we have objective, or belief-independent, knowledge of an entity that does not exist independently of our beliefs about its existence and nature? For example, if there is no way that therapy works independently of our beliefs about how therapy works, then we cannot know the workings of therapy objectively. (See Held, 2002, 2007, and Thomasson, 2003, for arguments about how there can be objective knowledge of mind-dependent entities, such as social/psychological kinds.)

The same holds true of causality. I am pleased to know that Fishman agrees that there are what he calls "causal mechanisms" (p. 11) in his pragmatic system of therapy. Evidently, I rushed to judgment in thinking otherwise, based on his rejection of causal laws in psychology (Fishman, 1999, pp. 8, 99, 2001, p. 280). But he is talking about "causality" (with my scare 
Round 3: Regarding Objectivity and Causality - A Rejoinder to Fishman and Miller

B.S. Held

Pragmatic Case Studies in Psychotherapy, http://pcsp.libraries.rutgers.edu

Volume 2, Module 4, Article 5, pp. 1-11, 10-16-06 [copyright by author]

quotes added) and I am talking about causality (without scare quotes). By this I mean that he gives causality no objective, or knower-/belief-independent, existence/ontological status (as do I), but instead reduces it to a "conceptual tool" (p. 11): “[Philosophical pragmatism's] causal mechanisms and principles don't purport to mirror the way the world objectively is, independent of any human perception and interpretation of it" (p. 11). If Fishman's "causal mechanisms" are conceptual tools within a perspective/knowledge system (i.e., a paradigm, language game, or most fundamentally, a web of belief held by some, which is what Fishman seems to suggest), then even the pragmatic utility of those "causal mechanisms" cannot be judged objectively - that is, judged independently of the beliefs about them of those particular others who share the relevant perspective/knowledge system or web of belief.

Similarly, he makes free will and determinism - traditional causal matters, to be suredependent on "how you look at it" (p. 12); for him there seemingly is no way that these causal entities are, independent of beliefs about how they are. If "how you look at it" depends on your (or any other knower's) particular knowledge system, with all the beliefs about causality that may be contained therein, then there can be no objective knowledge of free will and determinism by my definition.

\section{RONALD MILLER ON OBJECTIVITY AND CAUSALITY}

\section{Objectivity}

Whereas Fishman finds "objectivity" and "causality" within his pragmatism, Miller does not find those entities in his own theoretical system. Still, like Fishman, Miller (2006) thoughtfully lays out his important argument, which consists in his reasons for rejecting the possibility of objective knowledge and for rejecting the use of the term "cause," both in psychotherapy and psychology.

Early in his reply Miller asserts,

[C]linical knowledge is essentially a form of moral knowledge about how we, and our clients, ought to act in the world. . . . Clinical knowledge is not just about believing or justifying certain moral propositions, but also about being able to exercise moral judgment, make moral decisions, and engage in moral actions. ... [T]he justification for clinical actions (assessment and therapeutic practices) must involve moral principles or arguments about the fundamental meaning of moral terms like good and bad, right and wrong, respect and dignity, freedom and responsibility. Such definitions are not purely descriptive, but prescriptive and value laden. (p. 2)

That last sentence is crucial, and I return to it momentarily. Here note that on Miller's view, "many of the most serious disagreements . . . about theoretical approaches to diagnosis and treatment are essentially moral disagreements about certain aspects of the nature of the 'Good Life" (p. 2). Once the "meta-ethical argument" that all therapies "entail moral assumptions and presuppositions" (p. 3) is recognized, he says, "the door is opened to the first-level ethical or 
Round 3: Regarding Objectivity and Causality - A Rejoinder to Fishman and Miller

B.S. Held

Pragmatic Case Studies in Psychotherapy, http://pcsp.libraries.rutgers.edu

Volume 2, Module 4, Article 5, pp. 1-11, 10-16-06 [copyright by author]

moral debate itself as to which moral and ethical principles should be guiding interactions with our clients" (p. 3). About the latter, Miller concludes that consensus is unlikely: "across quite disparate moral communities, I do not see how it will be possible to develop agreed upon principles in the sense in which Held speaks of objective knowledge" (p. 13).

I am not sure I see any moral consensus in sight, either. But independent of the fate of any hoped-for moral realism/objectivism, my argument concerns the realism or objectivism of empirical claims, which moral claims (i.e., oughts or shoulds) are not (Held, 2005). Miller says that he is not clear about my "position on the moral aspects of clinical theory and practice" (p. 12). Fair enough, since I painted my moral landscape with only a broad brush. Relatedly, he also said, "I am not sure she agrees that all clinical positions are essentially and inevitably based upon moral assumptions and propositions (the meta-ethical argument)" (p. 3). Miller is right to wonder about this, not least because -- as it turns out -- I do not agree, and so I am glad that he asked for the needed clarification.

When I say that therapy is a "moral matter," I mean, after Miller (2006, p. 2), that therapists and clients are often confronted with questions about what they ought to do. In my target article I stated that "therapy is a moral matter, in which the therapist is obligated to work to understand the unique features of each client's suffering as well as possible, so that she can respond optimally to just this person's pain" (Held, 2006, p. 2). But I nonetheless agree with Tjeltveit (1999), who, in his highly nuanced Ethics and Values in Psychotherapy, defines ethics to include "both moral and nonmoral considerations," which translate into "obligations and aspirational ideals," respectively (p. 205). Tjeltveit believes that therapy is an ethical matter in that it contains both "moral and obligatory ideals" as well as "nonmoral and aspirational ideals" (p. 205), and he gives this example:

[I]t would have been good for Bob to develop insight; that was an aspirational ideal. But it was not obligatory for him to do so. We should not say he should have done so, or that it was immoral or wrong that he did not. There may be some situations, however, in which therapy goals involve moral obligations [e.g., helping a father to stop abusing his children]. (p. 205)

Thus, while helping a client pursue what is good is indeed an ethical matter, what is good is not necessarily obligatory - that is, it is not necessarily a moral matter. Miller, unlike Tjeltveit, does not distinguish between moral goods and nonmoral goods; he speaks of "good and bad" as well as "right and wrong" as "moral terms" (p. 2), and so I shall not pursue that distinction here, except to say that, like Tjeltveit, I will speak of the moral aspects of therapy as what should or ought to obtain over and above what is good. In any case, Miller is right that moral values, here meaning prescriptive oughts or shoulds, cannot be derived from empirical propositions. To attempt that would be to try to derive an "ought" (what should exist) from an "is" (what does exist) - in other words, it would constitute committing the "naturalistic fallacy" (Siegel, 1996). 
Round 3: Regarding Objectivity and Causality - A Rejoinder to Fishman and Miller

B.S. Held

Pragmatic Case Studies in Psychotherapy, http://pcsp.libraries.rutgers.edu

Volume 2, Module 4, Article 5, pp. 1-11, 10-16-06 [copyright by author]

But once we have accepted a therapeutic goal based on whatever form of ethical justification is in play (e.g., obligatory or aspirational), then there may be more and less effective ways of achieving it. Contrary to Miller's insistence upon the inseparability of means and ends (pace, Aristotle), I contend that determining more effective and less effective ways to achieve a goal is itself an empirical matter, one whose outcome can in principle be known with objectivity (i.e., independently of beliefs about its truth or nontruth). If, as Miller correctly says about me, I believe I should (i.e., I am morally obligated to) try to understand my client as a human being distinct in her own right (Miller, 2006, pp. 3, 12), then certain ways of relating to my client may be more likely to help me achieve that kind of understanding than are others; and this is in principle knowable objectively (i.e., regardless of the alleged Judeo-Christian origin of my goal, with all the beliefs about what ought to obtain that are contained in that tradition). Whether I should (i.e., am morally obligated) to seek to understand my client in those terms in the first place rests on moral principles, to be sure, and Miller is right to insist that no empirical observation (or what he calls "amoral descriptive or explanatory propositions," p. 4) can be used to derive such principles.

Now on to Miller's claim that we cannot see the same event unless we share the same moral perspective: "two observers who held widely disparate substantive moral views might actually perceive or see different events when observing the ostensibly 'same thing' happening" (p. 3). "From radically differing moral perspectives there is not a univocal description of the 'same case.' This is the problem of incommensurability that the post-modern philosophers in my view rightly address" (Miller, 2004, pp. 131-132, as cited in Miller, 2006, p. 11). This claim indeed constitutes a serious threat to an objectivist epistemology: if our moral frameworks, which might also consist in "webs of belief," determine what we actually observe, then there can be no knowledge of event or entity $\mathrm{X}$ that is independent of beliefs about the nature of event or entity X - that is, there can be no objective knowledge of X (see Held, 2002). Miller here uses the example of an observer who sees "a cold rejecting parent pushing their child away" whereas another observer may see "a disciplined parent, suppressing his/her emotional attachment, in order to encourage independent and self-sufficient behavior in the child" (p. 3). Later he uses the example of grief after the loss of a loved one: therapists who adhere to the DSM-IV can diagnose depression if the relevant "symptoms have persisted 8 weeks beyond the loss" (p. 11), whereas Miller finds that time limit horrific_- "to bounce back in 8 weeks would be a sign one might have had a rather limited love for the person lost" (p. 11). Thus, although some clinicians might see the person as depressed, others might see him "simply as grieving":

This is not a semantic difference only, for to see someone as "depressed" means one believes that person ought not to be feeling or acting as they are and they should be encouraged or even required to work to change their emotional/behavioral state. . . . [T]o see someone as grieving means one believes that this person is coping adequately with a difficult situation and that the community ought to continue to extend them care and concern without any demand that they change. (Miller, 2006, p. 11)

I contend that the issue is primarily a semantic one, and moreover that the "ought" can be separated from (i.e., is not derivable from) the "is." "Depressed" versus "grieving" are terms 
Round 3: Regarding Objectivity and Causality - A Rejoinder to Fishman and Miller

B.S. Held

Pragmatic Case Studies in Psychotherapy, http://pcsp.libraries.rutgers.edu

Volume 2, Module 4, Article 5, pp. 1-11, 10-16-06 [copyright by author]

with meanings, and if we cannot agree on the referents for the use of these terms (i.e., their "boundary" or "existential" criteria/conditions; see Thomasson, 2003), then we have a semantic difference that precludes rational discussion about them owing to the problem of (postmodern) incommensurability that Miller finds persuasive. But whether the clinician sees depression or grieving, she still must make an ethical (and in some cases a moral) decision about what to do (and what not to do). Would it be best to prescribe antidepressants, conduct cognitive therapy, attain intrapsychic insight, reassure the client that it is okay to feel depressed in these circumstances, try to "hold" the pain with empathy, rally the support of the client's community?

To be sure, what the clinician does depends (at least in principle) on what outcome the client desires - his goal. And whether a clinician should accept or reject a client's goal requires moral consideration of what, if anything, is obligatory in that particular circumstance (Tjeltveit, 1999). But once the clinician has accepted a goal, whether it is judged to be moral and obligatory or nonmoral and aspirational, some ways of proceeding may help attain that goal more than others, even if those ways differ with respect to different kinds of clients (or within different communities). And everyone can in principle know these empirical findings objectively - that is, independently of their own ethical/moral perspectives, including their beliefs about these matters (though they may value the findings differentially). So what is empirically true about certain kinds of clients can in principle be empirically true for all knowers. We are back to my distinction between "true for" and "true about" (see Held, 2006, p. 17). So too with Miller's example of promoting autonomy in children: if one thinks parents should pursue that goal (an ought), or that pursing that goal is a nonobligatory good (an aspiration), then some forms of childrearing may promote that goal better than others. Again, there is nothing relativistic epistemically about this, even though the most effective ways of promoting autonomy may differ as a function of the community in which families live, and that is an ontological matter.

And the same logic holds in case law: whether we ought to accept the death penalty for murder is a moral matter, which cannot be derived from what is. But if we do accept the death penalty based on the belief that it will help deter future murders, we must realize that we are then dealing with an empirical claim, which can in principle be assessed objectively- that is, its truth does not depend on anyone's beliefs about its truth (either, e.g., in Texas, where there is a death penalty, or in Massachusetts, where there is not). And so far I know of no evidence that supports that empirical claim about deterrence (although, for purposes of disclosure, I am no expert in these matters). And even if the empirical claim that the death penalty deters murders were true about those who live in Texas but not true about those who live in Massachusetts, any such existing difference would exist objectively (i.e., independently of beliefs about its existence). Therefore, the truth (or falsity) of a claim about that difference would not depend on anyone's beliefs about its truth (or falsity); that difference could in principle then be known objectively. And so any such existing difference would be true for all knowers who are capable of entertaining the evidence rationally enough, including those who live in Texas and Massachusetts. 
Round 3: Regarding Objectivity and Causality - A Rejoinder to Fishman and Miller B.S. Held

Pragmatic Case Studies in Psychotherapy, http://pcsp.libraries.rutgers.edu

Volume 2, Module 4, Article 5, pp. 1-11, 10-16-06 [copyright by author]

Again, "true for" (an epistemic matter) versus "true about" (an ontological matter). We cannot speak about one (epistemology) without the other (ontology). I conclude that Miller and I may remain further apart on the issue of objective knowledge than he suggests (p. 10), although we agree that moral judgments, such as whether there should be a death penalty, cannot be derived from empirical propositions of any sort, no matter how much evidential support/truth status an empirical proposition may enjoy. But for me at least, agreement is less important than is this opportunity for intellectual exchange itself.

\section{Causality}

The nature of causality in both the physical and the human world is such an intricate and thorny matter that I doubt that there will be philosophical agreement about it anytime soon. Accordingly, here I confine my response to Miller's reasons for rejecting the notion of causality — indeed, the very use of the term "cause" - in the human sciences.

Miller (2006) seems to appreciate the complexity of causality when he states,

We [Held and I] differ on whether it is useful to call the discovery of observed patterns in human behavior ... a form of causal explanation. I find it so contrary to what is meant by "causal explanation" in the physical sciences that I think it is confusing to do so and she does not .... [O]ne should only depart from common sense language when clarity requires it, and here I think it does. Conscious, planned, socially agreed upon, rule governed, and goal directed reasons for acting have so many properties that differentiate them from material and efficient causal explanations that I think using the same term for both is confusing and misleading. (p. 9)

Miller may well be right about a terminological source of confusion. However, unlike his solution, mine is not to throw out the rationally agentic baby with the causal bathwater but rather to work out an ontology of causality that befits human matters. Many have tried, and philosopher Edward Pols's rejection of the "received scientific doctrine of causality" (1998) along with his detailed explication of the "the complexity of causality" that inheres in "rational action" (2002) are good examples. But whether Pols's ontology of causality succeeds has no bearing on this point: though he does not use the word "cause," Miller (2004) himself appears to make causal claims nonetheless. Moreover, as far as I can tell, he puts forth those claims without the relativism that he says should qualify all clinical claims, and so I see them as objective claims - that is, their truth does not depend on beliefs about their truth, and so they are in principle true for all knowers (though they may not be true about all clients). I stated them in my target article (they appear in a section of Miller, 2004, entitled "Moral Engagement"), and I restate them here: (a) "Clients cannot develop moral reciprocity unless they first receive more than they can give" (p. 228); and (b) "By treating another person with respect, fairness, and compassion, the psychologist or psychotherapist performs a reparative moral function that helps the client not only to 'feel better' but also by promoting moral development to do better" ( $p$. 229). 
Round 3: Regarding Objectivity and Causality - A Rejoinder to Fishman and Miller

B.S. Held

Pragmatic Case Studies in Psychotherapy, http://pcsp.libraries.rutgers.edu

Volume 2, Module 4, Article 5, pp. 1-11, 10-16-06 [copyright by author]

I would translate these two claims to say that (a) receiving more than one can give can help cause the development of moral reciprocity; and (b) being treated with respect, fairness, and compassion constitutes a reparative moral function that can help cause people to feel better and do better. Whatever "feel better and do better" mean (i.e., they could perhaps be defined only relative to a community's values), the terms "respect," "fairness," and "compassion" are not relativistically qualified by Miller. Perhaps Miller meant to do so, but he did not. And this leads me to ask if we can understand/describe fairness, respect, and compassion independently of our language communities or moral perspectives (which Miller says we cannot do with other matters, such as those pertaining to child rearing and the loss of a loved one). If we cannot, then perhaps these claims should not be put forth with the objectivist/nonrelativist thrust I find in them, quite apart from the causality I also find in them.

Finally, there may be moral danger in removing the word "cause" from our psychological scientific vocabulary. If as agents we cannot rightly be said to affect ourselves and each other causally, then how can there be moral accountability for our actions? If Mr. McX is depressed because he lost his life savings (to use one of Miller's examples), and he lost his life savings because Mr. McY embezzled his funds, then Mr. McY caused him harm. Miller says that therapy must be about "facing human suffering," which for him "implies a sense of moral injury, of having been unfairly harmed, of not deserving the pain and misery that has been inflicted upon one" (Miller, 2004, pp. 23-28, as cited in Miller, 2006, p. 2). About this we agree. But if we take causality out of the therapeutic picture - both in scientific theory and in practice - then I am not sure that we can succeed in the reparative mission upon which Miller so rightly and impressively insists.

\section{REFERENCES}

Erwin, E. (1997). Philosophy and psychotherapy: Razing the troubles of the brain. London: Sage.

Erwin, E. (1999). Constructivist epistemologies and therapies. British Journal of Guidance and Counselling, 27, 353-365.

Fishman, D. B. (1999). The case for pragmatic psychology. New York: New York University Press.

Fishman, D. B. (2001). From single case to database: A new method for enhancing Psychotherapy, forensic, and other psychological practice. Applied and Preventive Psychology, 10, 275-304.

Fishman, D. B. (2006). Round 2A: Finding objectivity and causality in pragmatism-A response to Held. Pragmatic Case Studies in Psychotherapy [Online], Vol. 2(4), Article 3. Available: http://hdl.rutgers.edu/1782.1/pcsp journal Pragmatic Case Studies in Psychotherapy.

Haack, S. (2002). Realisms and their rivals: Recovering our innocence. Facta Philosophica, 4, 67-88.

Haack, S. (2003). Defending science -within reason: Between scientism and cynicism. Amherst, NY: Prometheus Books. 
Round 3: Regarding Objectivity and Causality - A Rejoinder to Fishman and Miller

B.S. Held

Pragmatic Case Studies in Psychotherapy, http://pcsp.libraries.rutgers.edu

Volume 2, Module 4, Article 5, pp. 1-11, 10-16-06 [copyright by author]

Held, B. S. (2002). What follows? Mind dependence, fallibility, and transcendence according to (strong) constructionism's realist and quasi-realist critics. Theory and Psychology, 12, 651-669.

Held, B. S. (2005). The "virtues" of positive psychology. Journal of Theoretical and Philosophical Psychology, 25, 1-34.

Held, B. S. (2006). Round 1: Does case study knowledge need a new epistemology? Pragmatic Case Studies in Psychotherapy [Online], Vol. 2(4), Article 2. Available: http://hdl.rutgers.edu/1782.1/pcsp_journal

Held, B. S. (2007). Psychology's interpretive turn: The search for truth and agency in theoretical and philosophical psychology. Washington, DC: American Psychological Association.

Miller, R. B. (2004). Facing human suffering: Psychology and psychotherapy as moral engagement. Washington, DC: American Psychological Association.

Miller, R. B. (2006). Round 2B: Facing human suffering-A response to Held. Pragmatic Case Studies in Psychotherapy [Online], Vol. 2(4), Article 4. Available: http://hdl.rutgers.edu/1782.1/pcsp_journal

Pols, E. (1998). Mind regained. Ithaca: Cornell University Press.

Pols, E. (2002). Rational action and the complexity of causality. Journal of Theoretical and Philosophical Psychology, 22, 1-18.

Rescher, N. (1997). Objectivity: The obligations of impersonal reason. Notre Dame: University of Notre Dame Press.

Siegel, H. (1996). Naturalism and the abandonment of normativity. In W. O'Donohue \& R. F. Kitchener (Eds.), The philosophy of psychology (pp. 4-18). London: Sage.

Siegel, H. (2004). Relativism. In I. Niiniluoto, M. Sintonen, \& J. Wolenski (Eds.), Handbook of epistemology (pp. 747-780). Netherlands: Kluwer Academic Publishers.

Smith, T. (2004). "Social" objectivity and the objectivity of value. In P. Machamer \& G. Wolters (Eds.), Science, values, and objectivity (pp. 143-171). Pittsburgh: University of Pittsburgh Press.

Thomasson, A. L. (2003). Realism and human kinds. Philosophy and Phenomenological Research, 67, 580-609.

Tjeltveit, A. C. (1999). Ethics and values in psychotherapy. London: Routledge. 